\title{
Pedagogical Implications, Possibilities, and Pitfalls of Offering a Semester 3 Credit Course in Nine Consecutive Days
}

\author{
Porter E. Coggins, $\mathrm{III}^{1}$, PhD, Victoria Hays ${ }^{2}$, DNP, PHCNS-BC, RN \& Kate Larson ${ }^{3}, \mathrm{PhD}$ \\ ${ }^{1}$ Associate Professor, Professional Education, Bemidji State University, 1500 Birchmont Dr NE \#35, Bemidji, MN \\ 56601, USA \\ ${ }^{2}$ Chair of Nursing \& Health Programs, University of Great Falls, Office of the Chief Nurse Officer, $130120^{\text {th }}$ St. S., \\ Great Falls, MT 59405, USA \\ ${ }^{3}$ Assistant Professor of Psychology, Bemidji State University, 1500 Birchmont Dr NE \#23, Bemidji, MN 56601, \\ USA
}

Correspondence: Porter E. Coggins, III, PhD, Associate Professor, Professional Education, Bemidji State University, 1500 Birchmont Dr NE \#35, Bemidji, MN 56601, USA

Received: May 17, 2016

doi:10.5430/ijhe.v5n3p45
Accepted: May 31, 2016

Online Published: June 7, 2016

\begin{abstract}
As colleges and universities consider the purpose, curriculum, delivery, and design of undergraduate degrees in the twenty-first century, part of that discussion must involve pedagogical implications of courses that are both content rich and time-condensed. A review of the literature on construction courses under these constraints indicates that there is a gap in the literature and educators could benefit from a principled approach that can serve as a template for designing such courses. To help fill that gap and generate continued discussion, we present pedagogical implications and pitfalls of offering a 3 credit, full semester applied statistics course for nursing majors in just nine consecutive days. Although a great deal of thought goes into course construction no matter the length of the course or the delivery format, running a full semester, three credit course in just nine days required special consideration. Attention to higher order thinking, cognitive load, and time management become critical. As schools consider ways to save students money, allow them to graduate sooner in order to enter the workplace sooner, and to give students incentive to matriculate at institutions which allow students a fast-track, our nine consecutive day course may serve as a model for entire degree programs based on that model.
\end{abstract}

Keywords: Condensed course, Pedagogy, Instructional design, Active learning, RN-BSN program

\section{Introduction}

\subsection{Current Questions in Higher Educations}

Colleges and universities face growing pressure to make education meaningful, relevant, and increasingly, time-valued. As economics continue to shape philosophies of education, the general public and policy makers are setting a high bar of accountability in post-secondary institutions with respect to both institutional and post-graduation student costs, course and degree relevance, and time to complete degrees (U.S. Department of Education, 2006, pp. x-xiii, 2). Among the many questions institutions are facing from the general public and policy makers include Why is the cost of post-secondary degrees so high?, To what extent should students bear the financial burden of a post-secondary education?, What is a reasonable cost-burden for students to be expected to carry after graduation?, What is the employment value of a post-secondary education?, Should universities offer degrees in the liberal arts in the economic environment of the world today?, and Why should a meaningful post-secondary degree program take so long to complete? Within the context of these questions, colleges and universities are considering ways to allow students to move more quickly from admission to graduation in non-traditional ways. Among innovations many schools have been moving toward over the past decade include mini-terms between typical main terms, extended summer school terms, weekend-only courses, and mini-terms between the end of the typical academic year and summer school. Currently a small number of universities in the United States allow students to graduate with their undergraduate degree in three years as is typical of universities in Australia, New Zealand, The United Kingdom, and Europe. 


\subsection{One Model Course}

One university in the Pacific Northwest in the United States our students in our Registered Nurse to Bachelor of Science in Nursing (RN-BSN) program are required to take a 3 credit applied statistics course (NRS 301 Applied Statistics in a Healthcare Context). We have offered this course over several years in an atypical course delivery model in just nine consecutive days. This model may serve as a course delivery model for other accelerated undergraduate degree programs. Although many schools offer weekend, month-long or two-week seminar courses, there are few examples of content rich, semester long courses offered on consecutive days that span two weeks or less. University - level, content - rich courses offered in the constraints of a time frame of nine consecutive days present significant challenges unique to this model and requires sensitive attention to aspects of cognition related to instructional design and pedagogy. As schools consider restructuring institutional costs and student debt burden, solutions include allowing students to graduate sooner in order to enter the workplace sooner, and to give students incentive to matriculate at institutions which allow students a fast-track to degree completion. Our course may serve as a model for an entire degree program that may in part meet the financial needs of higher education in the $21^{\text {st }}$ Century.

\section{Method}

\subsection{Participants and Demographics}

Our participants included three tenured or tenure track, doctorate degree - holding faculty from mathematics, education, and sociology. The doctorates were granted from the University of Idaho, Portland State University, and the University of West Virginia. All three instructors had taken multiple statistics and methodology coursework at the doctoral level and had previously taught research methods and statistics courses for majors in their content areas for at least one year.

\subsection{Integration of the Essentials in a Condensed Course Format}

The foundational document used to plan, implement and evaluate the Registered Nurse to Bachelor of Science in Nursing degree (RN-BSN) curriculum is based on the American Association of Colleges of Nursing's The Essentials of Baccalaureate Education for Professional Nursing Practice. The RN-BSN curriculum builds upon the arts, sciences, and humanities courses as a foundation for professional nursing. All students at one university in the Pacific Northwest of the United States must complete general education courses and specific pre-requisite courses for the nursing program; one of which is a nursing statistics course (NRS 301 Applied Statistics in a Healthcare Context).

The Essentials I (Liberal Education for Baccalaureate Education Generalist Nursing Practice) and Essentials III (Scholarship for Evidence Based Practice) were used to guide the development of the course objectives for the nursing statistics course. All assessments and assignments were developed based on the course objectives. The course-level, individual student learning outcomes and objectives are consistent with The Baccalaureate Essentials and reviewed annually. Lastly, the principles and student learning outcomes from this course has served as a foundation for the students to further apply these concepts in the evidence-based nursing course they enroll in the following semester.

\subsection{Course Specifics}

Our course evolved from the first offering to the form presented here. Initially, the course was developed with time split equally between lecture and lab. Over several years from that initial offering, the division between lecture and lab was removed, the typical introductory set of statistical topics was broadened, and the archaic approach of hand calculation was replaced to align more closely with the principles of an applied course. The daily course content objectives were developed specifically, and only, with the university's RN-BSN requirements and American Association of Colleges of Nursing (2008) Essentials I and III in mind; this was not a course for statistics or mathematics majors. However, our course content focus was consistent with the general recommendations of Hayat et al. (2013, p. 331) that the course instructors of nursing statistics "...emphasize and demonstrate the relevance and importance of statistical knowledge and applications in the nursing sciences." and the recommended teaching objectives for BSN degree students to "... include a strong foundation in critical thinking and an introduction to statistical literacy."

Briefly, our content topics were as follows. Day 1: Pre-assessment, introduction to topics relevant to both understanding empirical, quantitative research in the healthcare field, and designing an empirical, quantitative study, Day 2: Descriptive statistics, box plots, histograms, stem-and-leaf plots, and scatter plots, Day 3: Independent t-test and Mann-Whitney U-test, Day 4: Dependent t- test for Paired Samples and Wilcoxon Matched Pairs test, Day 5: 
Single Factor ANOVA and Kruskal-Wallis H-test, Day 6: Repeated Measures ANOVA and the Friedman Test, Day 7: Correlation and single variable regression, Day 8: Chi-Square, Fisher Exact test, McNemar's test, and Odds Ratio, Day 9: Group presentations of empirical, quantitative study designs, and post-assessment. The first day and last day of the course were both only two hours in length. The first day was devoted to developing research concepts required for empirical, quantitative study design group-presentations that were presented on the last day. All materials used for this course may be obtained by writing the correspondence author.

\section{Findings and Discussion Concerning Possibilities, Pitfalls, and One Hard Question}

\subsection{Lessons Learned in Offering a Nine Consecutive Day Condensed Course}

Our purpose of this report is to share our observations of offering a content - rich, condensed course in nine consecutive days, in the context of principled, research - based pedagogy. As our course evolved from the typical introductory statistics course for traditional non - STEM majors to a truly applied course, we learned several valuable lessons along the way that clearly indicated that courses of this type, under these constraints require careful attention to several aspects of educational psychology and pedagogy if the course was to be meaningful for students. Our report here is not an empirical study on effectiveness (per se) from dependent measures methodology of student achievement, rather, our report is based on the qualitative aspects of how we addressed our content in those constraints. Because there is a complete void in the literature of the implications, how - to, or empirical research on effectiveness of offering a college course in this format, we present our observations with the hope that our journey may be the start of a conversation and empirical research in the area of offering semester length courses in a condensed, consecutive day format.

\subsection{Meaningful and Active Student Engagement in the Learner-Centered Classroom}

The past 30 years reflect a tremendous educational change in content delivery, shifting from a traditional lecture format to active learning in the classroom that now includes a new level of student engagement that was not required in the past. Today, demonstrations, activities, and exercises in the classroom require students to engage in higher order thinking (problem solving, decision making, creativity) during class time. The university lecture has both an historical and practical significance. Prior to the advent of the printing press, and before the availability of printed material, lecturing was an important mode of conveying information to a group of people. From a practical aspect, one lecturer could transmit information to as many listeners as the space to accommodate them and within the limits of hearing. Of course well - planned and delivered lectures can spark interest and curiosity, but typically, most university lecturers are not engaging orators. In fact the biggest challenge students typically face in traditional lecture courses is to listen to and transcribe the lecture. The difficulty that a lecturer faces is engaging students in higher levels of cognitive processing, that are elements of active learning, found for example in the categories of Bloom's revised taxonomy (Anderson et al., 2001).

For example, Mayer (2001) defines active learning through selecting, organizing, and integrating, where the "Learner pays attention to relevant words and pictures in a multimedia message to create a word base and an image base" (p. 53), the "Learner builds internal connections among selected words to create an [sic] coherent verbal model and among pictures to create a coherent pictorial model" (p. 53), and the "Learner builds external connections between the verbal and pictorial models and with prior knowledge" (p. 53). So, in Mayer's model, active learning is a purposeful, deliberate behaviour by the learner who engages cognitive processes to make sense of the material beyond simply listening and note taking. Michael (2004) approaches a model of active learning through the concept of meaningful learning. "Meaningful learning is learning with understanding. When students achieve a level of meaningful learning, they are able to do things with the information they are acquiring; they can use their knowledge to accomplish appropriate tasks" (Michael, 2004, p. 227). For Michael, learning means that the learning process is a cognitive process that allows the student to use the information received in an active manner, which again goes beyond passively listening and simply taking notes. In other words, active learning is meaningful by his definition of meaningful learning because there is a connection between the cognitive aspect of information reception and new behaviour based on that information. Kolb (1984) approaches a form of active learning through his Experiential Learning Theory and writes "To learn is not the special province of a single specialized realm of human functioning such as cognition or perception. It involves the integrated functioning of the total organism- thinking, feeling, perceiving, and behaving" (Kolb, 1984, p. 31), and further states "Learning is the major process of human adaptation... Therefore it encompasses other, more limited adaptive concepts such as creativity, problem solving, decision make, and attitude change that focus heavily on one or another of the basic aspects of adaptation" (p. 32). Kolb recognizes that learning is a multidomain process that affects the total person and requires more on the part of the learner than simply listening or note taking. 
When applied to the classroom, all three of those models shift the what to how, and that how becomes at least as important as what we do in the classroom. In other words, inviting students to become actively engaged, to turn on their higher order thinking skills becomes as important as the very information we are trying to help our students acquire. Further, when this happens, learning is more that simple acquisition of information as students begin to connect the dots by actively engaging in classroom topics through aspects of higher order thinking.

If every class ought to make active, meaningful learning the modus operandi of the classroom pedagogy, then this is especially true for a time - condensed, content - rich course where every minute counts (much more so than in static, lecture based courses that stretch over 16 weeks). So, how did we implement active, meaningful learning in our course over nine days? We did this by applying principles espoused by Mayer (selecting, organizing, and integrating), Michael (requiring students to demonstrate understanding through higher levels of Bloom's revised taxonomy), and Kolb (through a holistic view of learning for the whole person), and repeatedly asking students to engage in critical thinking, problem solving, and decision making in multiple opportunities throughout each day rather than simply (read passively) listening, taking notes, and later doing homework.

In the context of our nine consecutive day intensive applied statistics course, students were required to actively work to construct, integrate, and apply statistical knowledge, in short, to build understanding in a broad sense of the word through active engagement with the material rather than simply listening and taking notes to be memorized for the typical hour - exam. A learner - centered pedagogical model is one where the learning responsibility is revealed in the student - faculty dynamic in which education now represents shared knowledge through shared responsibility (Larson, 2008). Within a learner - centered environment, educators are facilitators of knowledge building and understanding, taking context and student feedback into consideration as part of a learning feedback cycle. The primary objective in a learner - centered course is to actively engage students in the process of learning, understanding, and critical thinking (McKeachie and Svinicki, 2006). This model is markedly different from the days of the professor as a removed, expert figure who addressed the class (Fuhrmann and Grasha, 1998). Facilitators of learning, on the other hand, actively engage with their students in the process of knowledge construction, by modeling problem solving, critical thinking, and application (Larson, 2008). "Knowledge is not passively received but actively built up by the cognizing subject" (von Glasersfeld, 1989, p. 162). We did this by inviting student participation as much as possible in a variety of meaningful activities centered around our course learning objectives. For example, in our course, applied statistics in a healthcare context, we opted out of asking students to calculate anything by hand. We did this for several reasons. First, although hand calculations are important for science, engineering, mathematics, and statistics majors (part of the STEM fields of science, technology, engineering, and mathematics) to allow them to "see under the hood" and gain conceptual understanding at a deep level, hand calculations for those not in such fields detracts from the learning objectives at hand. That is, the inappropriate use of hand calculation from the student perspective is often confusing and pointless, requires a level of numerical fluency beyond the comfort and confidence levels of most non - STEM students. In practice, critical calculations are left trusted software, not hand calculations. In fact, many important data sets in real life are simply impossible to calculate by hand. So, the argument for hand calculation is vacuous from pedagogical reasons in an applied statistics course. The second reason that we opted out of hand calculation is that we wanted students to think about what test was appropriate for a data test, how to run the test with the push of a button, and how to find and interpret the output of the test. For an applied course, these learning objectives lead to students engaging with the material on a conceptual level that steers student clear of the forest of details encountered in hand calculation. Thirdly, we opted out of hand calculation because time was a critical and precious commodity in our nine consecutive day format, and hand calculations are tedious and time consuming. We are able to cover many more statistical inference tests by not stopping to teach hand calculations to a few tests with simple data sets.

\subsection{Active Student Engagement by Directing Student Attention}

Even with explicitly stated instructional objectives where students may have a sense of where we are leading them, it is possible that their attention, even when devoted to the course in the moment, may actually drift to irrelevant or unimportant issues. Some examples of attentional drift include wondering about superfluous information recorded in a printout, wondering why we are not discussing other options in a software application, wondering about details involved in a future step in a process before understanding the current step in a process, wondering about the layout of information in a typed page, etc. All of these types of attentional drift may be important at some point, but as instructors, we know the path of the journey we are taking students on and what we want or need them to see even when they mistakenly think they know it too. Unless we consciously recognize this divergence in seeing the big picture from the details it is very easy for attentional drift to occur. Further, when we consider how we allow students to actively engage, we can minimize students falling off the path of our intended learning objectives. These 
distractors that contribute to attentional drift are related to extraneous processing which Mayer defines as "Cognitive processing during learning that does not support the objective of the lesson" (Mayer, 2011, p. 62). Of importance to note is that during attentional drift, students are focused on things other than those that lead them to meeting our learning objectives. By directing student attention to the most important and critical information, students had the opportunity for creating appropriate schema of that information, and integrating the new information with relevant prior knowledge (Mayer, 2001, Figure 3.5, p. 53). For example, to facilitate directing student attention to critical course information when introducing software, we explicitly showed students that there are many functions that we did not need to pay attention to at present, then we explicitly directed student attention to what we needed to attend to on the screen, asked students to find and point to that information, and reiterated that we were going to use this information and why we were using it. We did the same thing when showing printed output of statistical tests. We helped students focus on the important components by explicitly directing their attention to what was important and key information to direct attention, and reduced attentional drift by specifically and intentionally directing student attention to distractors to ignore.

\subsection{Active Student Engagement by Cumulative Questions and the Opportunity to Reflect}

Beginning in the third year, we added two cumulative reviews to our day on all days following the first day. We engaged students by starting each class with small group discussions of cumulative questions and scenarios from all previous classes for twenty to forty minutes, and did the same after the new content topic of the day was developed in class. This process is consistent with the notion of Priming Activities in which students are given "...carefully and deliberately designed homework...pre-class activities [that] expose students to foundational content and specific critical thinking before the class" (Ruckert et al., 2014, p. 5). Adopting this pedagogical technique in our class meant that we used a cumulative review at the start of each class rather than homework since homework was devoted to completing their cumulative final exam and group project, and in itself served as a daily opportunity to reflect on the course material. The cumulative review provided an opportunity for students to assimilate and accommodate in a Piagetian sense (Piaget, 1977) by correctly placing prior knowledge from previous class sessions into their current schema of course concepts. This review was critical for catching misunderstandings and correcting them before those misunderstandings became embedded into their schemas. An important component of schema development is scaffolding. In scaffolding, the instructor provides strong support and helps students to develop metacognitive skills to become self-regulated and autonomous in their learning to help them think about their own individual learning process (MacDougall, 2008, p. 223; van Merriënboer, Kirschner, and Kester, 2003, p. 5). We made conscious effort to scaffold through the use of a consistent class structure embedding the cumulative reviews into each morning, and in the development of metacognitive strategies through the process of continuing to ask themselves what they know, how the pieces fit, what things they are still fuzzy about, and what things are still outright confusing to themselves.

\subsection{Active Student Engagement in Presenting New Material}

After the cumulative review, faculty introduced new content (which in our specific case was a new statistics application) in the form of a scenario that students were asked to try to solve based on prior knowledge. After a discussion, students found that this new problem fell outside of their growing statistical schema and their current knowledge base was insufficient. This new problem bridged prior knowledge to the new learning objective(s) and content material. This was an opportunity to begin deep learning through questioning (Mayer, 2011, p. 74). Through a discussion with students, faculty presented conceptual ideas, developed concept maps showing the relationship between prior and new knowledge, stepped through worked scenarios using software, and discussed how to interpret and use the results to answer questions from those examples. These scenarios engage students in the construction of knowledge and understanding, giving them the opportunity to discuss, problem solve, and then reflect on what they have experienced (Bonwell, 1996; Bonwell and Eison, 1991; McKeachie, 1999). This active learning emphasis challenged students to cognitively construct patterns in information, organize into meaningful information, and understand when to use and retrieve this information (Bransford, Brown, and Cocking, 2000). Engaging students in an active learning approach affords them the opportunity to develop critical thinking and application skills (Burbach, Matkin, and Fritz, 2004; Perry, Huss, McAuliff, and Galas, 1996), which are especially important attributes for our students as they prepare to enter the healthcare field. At this point, students were given an additional opportunity to clarify thinking by turning to a fellow student, sharing notes, and then identifying the construct they understand and the construct that is still unclear, then writing questions on note cards for the instructor to answer in discussion.

\subsection{Active Student Engagement Concept Maps and Chunking}

Although it was tempting, and perhaps almost natural to want to plow straight through all of our content without stopping, we recognized that for reasons of cognitive load (discussed below) and the advantages of chunking we 
could maximize student learning by the less is more principle. We did this by breaking the learning objective into small chunks and take advantage of segmenting in which "People learn better when a complex lesson is presented in manageable parts." (Mayer, 2011, p. 68), and working memory management (Mayer and Moreno, 2003, p. 47). We considered each learning objective as a chunk, and then embedded smaller specific chunks of attributes into the larger chunk. Then, we asked students to help us talk through and diagram the information in the form of color-coded concept maps showing the relationship between various attributes of material to date, and did this from multiple perspectives by varying the attribute headers each time we added new information.

The value of concept maps has been reported at lease since 1970 by Novak and others, and more recently in 2010 where he describes the value of " "expert skeleton" concept maps" which are "...prepared by an expert in the knowledge domain to guide and "scaffold" learning" (Novak, 2010, p. 27). Recently, Erdoğan (2016) reported the results of a meta-analysis on the use of concept maps and found that students who used concept maps had significantly greater academic success than students who did not (Erdogan, 2016). Passmore argued for the use of student generated concept maps "...for growing their conceptual understanding, document their existing knowledge, gain new understanding, and then relate the new information to what they already know" (2014, p. 407). Concept maps can also benefit student learning through Mayer's Multimedia Effect for Retention in which "...deeper learning occurs when learners are able to integrate pictorial and verbal representations of the same message" (Mayer, 2001, p. 79). We also made use of this effect by drawing labeled diagrams for all inference tests as often as possible and as appropriate to the type of inference test under discussion. But, does concept mapping have any effect on summative assessment scores, or is this just a filler or activity high on engagement but low on academic value? To that question, Jaafarpour, Aazami, and Mozafari (2016) reported that indeed, students who engaged in organized concept mapping significantly outperformed students who did not use concept maps in cumulative tests. We then took a short break between each learning objective to provide students time to reflect on the material and prevent overloading working memory and adding to cognitive load.

\section{Attend to Cognitive Load}

\subsection{Cognitive Load and Working Memory}

In planning an effective implementation, it was essential to consider the implications of cognitive load theory (Leppink, van Gog, Paas, \& Sweller, 2015; Paas, Renkl, \& Sweller, 2003; Sweller \& Chandler, 1991; Sweller \& Chandler, 1994; van Merriënboer, Kirschner, \& Kester, 2003) and working memory limitations (Hoffman, et al. 2008, p. 471; Leppink, van Gog, Paas, \& Sweller, 2015, p. 209). Further, by specifically directing students what to look at and what to ignore in the input and output of statistical software, we were able to eliminate extraneous cognitive processing which is more urgently needed for processing essential information rather than sorting through irrelevant information and trying to fit it into their schemas (Mayer, 2011, p. 62). Doing this also took advantage of Mayer's Coherence Effect for Retention in which student retention increases when interesting, but irrelevant words and pictures are not included in lessons, and when lessons are "...short and to the point" (Mayer, 2001, p. 133). This was especially important given our strict time constraint and the value of time in this condensed course format.

\subsection{Effect of Cognitive Load on Learning}

One result of an increase in cognitive load, as is likely in a condensed course of new and dense information, is that working memory processing can be quickly overloaded leading to learning shutdown in which students quickly begin to feel overwhelmed and lost, and risk emotional burnout and a sense of despair because "...many members of a population may have extreme difficulty dealing with so many elements simultaneously" (Sweller and Chandler, 1994, p. 189). That point also directly relates to our position stated above regarding how easy it is for non - science major students to get lost in the details of hand calculations for statistical tests, and again why we opted to not follow that traditional, but pedagogically flawed process. Recognizing this danger can help instructors to realize that "... support for novice learners must be fully embedded in the learning tasks or task environment to be effective" (van Merriënboer, Kirschner, and Kester, 2003, p. 6). To help minimize this, in addition to points made above, the university imposed entrance requirements for the degree program, frontloaded this course with workshops in both writing and spreadsheet use, and insured immediate technical support when needed. Further, helping students to develop appropriate schemas in statistics (for example the relationship between data type, number of data in a set, and distribution with respect to appropriate statistical inference tests) “... reduce[s] cognitive load by permitting us to ignore most of the information impinging on our senses." (Sweller and Chandler, 1994, p. 187). Recently, Leppink, van Gog, Paas, and Sweller have reported the "additive effects" of intrinsic and extrinsic cognitive load: "In the recent reconceptualization, however, only intrinsic cognitive load and extraneous cognitive load are assumed to be additive; ... the sum of intrinsic and extraneous cognitive loads should be should be within the capabilities of 
working memory." (Leppink, van Gog, Paas, \& Sweller, 2015, p. 210). In other words, cognitive load has an accumulating effect that can encroach on working memory space and inhibit cognitive processing.

\section{Pitfalls of Offering a Time-Intensive Course}

\subsection{Pitfall of Anxiety and Stress}

Hagen et al. cite several studies which indicate that "...many undergraduate students approach statistics courses with considerable fear, anxiety, and ambivalence" (2013, p. 950). This is especially true for the students enrolled in our degree completion program, and likely true of most American students who have to take any mathematics course to meet degree requirements. MacDougall suggested that "...a key message which needs to be communicated is that it is okay, even normal, to find the subject matter difficult" (2008, p. 225). By minimizing or trivializing real student fear associated with this class, we risk alienating students by not taking their anxiety seriously and in doing so, it is easy ignore the impact of stress on higher order thinking. Our students typically entered this course with extreme anxiety because most of them were returning to school after years of employment in the healthcare field. Typically, their previous experience with their last math course in college was just to fulfill their graduation requirement. In contrast, by validating student concerns up front, and assuring them that although this course typically does have a reputation for creating anxiety, we are committed to creating a meaningful learning environment based student engagement with the material rather than rote learning (Passmore, 2014, p. 401). We learned the importance of developing a rapport with our students that created a safe, risk-free environment that encouraged effort in spite of perceived failure, and that we were there together to encourage, support, and pick each other up.

\subsection{Pitfall of Ignoring Cognitive Load}

First, ignoring the effects of cognitive load can immediately dishearten students on the very first day due to steep learning curves for students unfamiliar with word processing, spreadsheets, or computers in general, leading to feeling overwhelmed by the amount of material in the course, and the necessity to hold several seemingly unrelated pieces of information in working memory while trying to connect them together. Frontloading with computer familiarity can help reduce anxiety and cognitive load. In this particular program, this is done by requiring students to now have a working knowledge of Microsoft Office Suite $\odot$ prior to beginning the program. Second, ignoring the effects of cognitive load with respect to attention span can quickly overload student working memory to the point where new information in a lecture is no longer processing in working memory and in effect is lost. A well developed 50 minute lecture that holds student attention takes careful planning; a four hour lecture is likely a complete waste of meaningful learning time because of concentration fatigue while attempting to attend to detailed information over long periods of time (Mizuno, et al., 2011). Further, listening for lengths of time without the opportunity to either reflect or directly engage in the material increases the cognitive overload and lack of meaningful processing of content and decreases concept formation.

\subsection{Pitfall of Assuming Students Understand Just Because They Talked About It!}

We initially assumed in the first few years that students understood concepts just because we gave students the opportunity to discuss questions related to them. Of course, this pitfall applies to any course regardless of the delivery format and time - frame, but because time is an especially precious commodity in a condensed course, lost time has a compounding effect because students have less time to pick up the pieces (in a manner of speaking) later in the course. When we realized that our moving mouths did not actuate concept - building in our students, we reorganized our day to allow purposeful reflection through the cumulative reviews described above. Another interesting related misconception on our part was that we initially thought the best solutions to each question would bubble to the surface through the group discussion. We were quite wrong in that assumption. One instructor of the course actually went over the discussion questions with the class when the groups returned and discovered a disconnect between the solutions arrived at and the best solution to the questions. This was a "light-bulb" moment for the other course instructor and we then realized the importance of actually debriefing by taking the time to go over questions and answers in the class after small group discussions. Our initial pitfall as faculty was to confuse group discussion with the ability of the group to identify misconceptions in discussion. Of course, at times students were able to disambiguate in their group cumulative reviews, but not always, and our failure to explicitly check for understanding after every cumulative review meant that some students were holding to unresolved misconceptions. It is possible that many minds might not be experienced enough yet to catch misconceptions that arise in a group discussion. 


\subsection{Pitfall of Assuming that Seeing is Understanding}

We incorrectly assumed just because students saw pre - drawn, textbook concept maps and flowcharts of statistical inference tests and topics they were capable of building their own concept maps as conceptual representations of those they had seen, as if they built their maps based on memorization of those maps and flowcharts. In reality, seeing is not understanding. In response to this pitfall, we identified two reasonable solutions to help avoid this pitfall.

One is to co-create concept maps together in class as a class exercise in organizing the content. We drew multiple maps completely, then redrew from another "angle" by varying the headers for rows and columns to give multiple perspectives of the interrelationships between headers such as group size, independent versus dependent variables, and parametric versus non-parametric tests. Further, because color can be used as an organizational tool, we modeled color - coded concept maps and worked through constructing them in class from scratch every day as a culminating activity to highlight, compare, and contrast all of the inferential statistics tests introduced to date. By having students draw and color - code the maps with us in class, we gave them the opportunity to organize and relate the information from many perspectives. We constructed our color - coded concept maps using an overhead interactive projector with color pens. Our projector arrangement was such that we had a very tall front wall that had a special projector screen paint that allowed us to write on the wall with the projector pens.

Several ideas occurred to us after the fourth year to further help us avoid the pitfall including using student generated concept maps as a form of assessment (Passmore, 2014, pp. 411-412) to check for student understanding as a formative or summative assessment by either groups or individuals, and going over the concept maps as soon as possible after they are created to immediately catch and correct misconceptions. Another form of formative assessment would be to allow students an additional opportunity to check their understanding by use of a quick-write Minute Paper giving students one minute to reflect and write on a topic and then collects and reviews the papers to verify whether students were on track or not. Instructors can quickly identify where misinformation and misunderstanding exists. The Minute Paper facilitates the process of scaffolding and, most importantly, construction of individual knowledge and understanding by identifying misconceptions.

\subsection{Pitfall of Wasted Time}

Because time was an especially valuable commodity in this course format, another pitfall to avoid was wasted time. In a content rich course, it is especially important to ensure that time is not wasted with busy-work, dead-air time, broken technology, or activities that generated high extraneous cognitive load in which students are engaged in irrelevant cognitive tasks which are "...not directed to schema acquisition and automation" (Sweller and Chandler, 1994, p. 192). Critically, unlike a weekend course that may last for several months, there is no opportunity in a content rich nine consecutive day model for either the instructor or the student to "catch up" due to lack of preparation. In a weekend course, both instructor and student have time to regroup, complete whatever was not completed, and catch up later. Of course, this catch-up time is also true of typical Monday-Wednesday-Friday or Tuesday-Thursday courses where there is at least one day between classes that can be used to catch up. In this nine consecutive day model, it is unwaveringly essential that each minute of each day be fully and carefully planned to avoid lost time that cannot be recovered.

\section{One Hard Question}

\subsection{The Question of Time for Processing}

In an attempt to save students and taxpayers money, to speed up graduation in order to allow graduates a quicker path to employment, dare we risk shortchanging the time needed to reflect on concepts embedded in course content? The best solutions in problem solving, creativity, and decision making do not necessarily avail themselves in two weeks, four weeks, or even in the time-span of a typical 16 week course. Colley, Bilics, and Lerch (2012) reported the positive impact that purposeful reflection can have on aspects of metacognitive processing. Although we eventually recognized the importance of reflection through the process of thinking back and thinking over in our daily cumulative reviews, we suspect that without empirical evidence that the long - term effects of deep learning may not develop over such a short period of time, no matter how intensely our students attend to the course material. Therefore, we must ask until there is research - based evidence, whether a nine consecutive day course model is appropriate for all courses, and invite the academic community to join the discussion on this hard question. Until the research is clear on this open question, one possible solution to is to offer a follow - up course, a Part 2, in the future for each condensed course offered to revisit course material and learning objectives initially addressed, and give the opportunity to reflect over the initial course material. 


\section{Conclusion}

With increasing pressure to deliver undergraduate degrees in a cost-effective and timely manner in the United States, colleges and universities have been exploring alternatives to current practice that can help alleviate concerns expressed by students and policy makers. One unique solution that may play an integral role toward that end for a content rich course is three credit, semester long course offered in just nine consecutive days. Unlike a weekend course spread over a month or more in a typical semester, the nine consecutive day course offered unique challenges that have not been explicitly considered in the literature. We offer here our experience, insights, and challenges from conducting such a course for those who wish to consider this type of course model as one facet of a multifaceted solution to delivering undergraduate degrees that are cost - effective and timely. We approached our course design by implementing aspects of meaningful learning, attention, working memory capacity, considering pitfalls of ignoring cognitive load, anxiety, assumptions about students, and time use. None of these design aspects are new, but what is unique is the urgent need to ensure that all of these facets of learning are critically accounted for in order to successfully present a meaningful class to students. We hope that our experience will generate discussion among faculty and administrators that will lead to fruitful solutions to some of the issues facing colleges and universities today with respect to accountability. Finally, it should be noted that the context of our course was a content rich applied statistics course for nursing students as part of their undergraduate degree in nursing.

\section{Acknowledgements}

The authors wish to express their deep gratitude to our students who participated in this journey, and all of the anonymous who offered valuable, constructive comments on our manuscript.

\section{References}

American Association of Colleges of Nursing. (2008). The essentials of baccalaureate education for professional nursing practice. Washington, DC: Author.

Anderson, L. W., Krathwohl, D. R., Airasian, P. W., Cruikshank, K. A., Mayer, R. E., Pintrich, P. R., ... Wittrock, M. C. (2001). A taxonomy for learning, teaching, and assessment: A revision of bloom's taxonomy of educational objectives. NewYork, NY: Longman.

Bonwell, C. C. (1996). Enhancing the lecture: Revitalizing a traditional format. In T. E. Sutherland \& C. C. Bonwell (Eds.), Using active learning in college classes: A range of options for faculty (pp. 31-44). San Francisco: Jossey-Bass. http://dx.doi.org/10.1002/t1.37219966706

Bonwell, C. C., \& Eison, J. A. (1991). Active learning: Creating excitement in the classroom (ASHE-ERIC Higher Education Rep. No.1). Washington, D.C.: George Washington University, School of Education and Human Development.

Bransford, J. D., Brown, A. L., \& Cocking, R. R. (2000). How people learn: Brain, mind, experience, and school. Washington, DC: National Academy Press.

Burbach, M., Matkin, G., \& Fritz, S. (2004). Teaching critical thinking in an introductory leadership course utilizing active learning strategies: A confirmatory study. College Student Journal, 38(3), 482-493.

Colley, B. M., Bilics, A. R., \& Lerch, C. M. (2012). Reflection: A key component to thinking critically. The Canadian Journal for the Scholarship of Teaching and Learning, 3(1). Article 2. http://dx.doi.org/10.5206/cjsotl-rcacea.2012.1.2

Erdoğan, Y. (2016). An investigation of the effectiveness of concept mapping on Turkish students' academic success. Journal of Education and Training Studies. 4(6), 1-9. http://dx.doi.org/10.11114/jets.v4i6.1380

Fuhrmann, B. S., \& Grasha, A. F. (1998). The past, present, and future in college teaching: Where does your teaching fit? In K. A. Feldman \& M. B. Paulsen (Eds.), Teaching and Learning in the College Classroom ( $2^{\text {nd }}$ ed., pp. 5-35). Boston: Pearson Custom Publishing.

Hagen, B., Awosoga, O., Kellett, P, \& Die, S. O. (2013). Evaluation of undergraduate nursing students' attitudes towards statistics courses, before, and after a course in applied statistics. Nurse Education Today, 33(9), 949-955. http://dx.doi.org.10.1016/j.nedt.2012.11.005

Hayat, M. J., Eckardt, P., Higgins, M., Kim, M., \& Schmiege, S. J. (2013). Teaching statistics to nursing students: An expert panel consensus. J Nurs Educ, 52(6), 330-334. http://dx.doi.org/10.3928/01484834-20130430-01 
Hoffman, B., McCrudden, M. T., Schraw, G., \& Hartley, K. (2008). The effects of informational complexity and working memory on problem-solving efficiency. Asian Pacific Educational Review, 9(4), 464-474. http://dx.doi.org/10.1007/BF03025663

Jaafarpour, M., Aazami, S., \& Mozafari, M. (2016). Does concept mapping enhance learning outcome of nursing students. Nurse Education Today, 36(13), 129-132. http://dx.doi.org/10.1016/j.nedt.2015.08.029

Kolb, D. A. (1984). Experiential learning: Experience as the source of learning and development. Englewood Cliffs, NJ: Prentice-Hall, Inc.

Larson, K. A. (2008). Storytelling as an active learning strategy in introduction to psychology courses. (Unpublished doctoral dissertation). Walden University, Minneapolis, Minnesota.

Leppink, J., van Gog, T., Paas, F., \& Sweller, J. (2015). Cognitive load theory: researching and planning teaching to maximize learning. In J. Clelend \& S. J. Durning (Eds.), Researching medical education (pp. 207-218). Oxford, UK: Wiley Blackwell. http://dx.doi.org/10.1002/9781118838983.ch18

MacDougall, M. (2008). Ten tips for promoting autonomous learning and effective engagement in the teaching of statistics to undergraduate medical students involved in short-term research projects. Journal of Applied Quantitative Methods, 3(3), 223-240.

Mayer, R. E. (2001). Multimedia learning. Cambridge, UK: Cambridge University Press. http://dx.doi.org/10.1017/CBO9781139164603

Mayer, R. E. (2011). Applying the science of learning. Boston, MA: Pearson.

Mayer, R. E., \& Moreno, R. (2003). Nine ways to reduce cognitive load in multimedia learning. Educational Psychologist, 38(1), 43-52. http://dx.doi.org/10.1207/S15326985EP3801_6

McKeachie, W. J. (1999). McKeachie's Teaching tips: Strategies, research, and theory for college and university teachers ( $3^{\text {rd }}$ ed.). New York: Houghton Mifflin

McKeachie, W. J., \& Svinicki, M. (2006). McKeachie's Teaching tips: Strategies, research, and theory for college and university teachers $\left(12^{\text {th }} \mathrm{ed}\right.$.). Boston: Houghton-Mifflin.

Michael, J. A. (2004). Mental models and meaningful learning. $J$ Vet Med Ed, 31(1), 227-230. http://dx.doi.org/10.3138/jvme.31.1.1

Mizuno, K., Tanaka, M., Yamaguti, K., Kajimoto, O, Kuratsune, H., \& Watanabe, Y. (2011). Mental fatigue caused by prolonged cognitive load associated with sympathetic hyperactivity. Behavioral and Brain Functions, 7(17), 1-7. http://dx.doi.org/10.1186/1744-9081-7-17.

National Research Council. (2011). The Future of nursing: Leading change, advancing health. Washington, DC: The National Academies Press.

Novak, J. D. (2010). Learning, creating, and using knowledge: Concept maps as facilitative tools in schools and corporations. Journal of e-Leaning and Knowledge Society, 6(3), 21-30.

Paas, F., Renkl, A., \& Sweller, J. (2003). Cognitive load theory and instructional design: recent developments. Educational Psychologist, 38(1), 1-4. http://dx.doi.org/10.1207/S15326985EP3801_1

Passmore, G. (2014). Concept mapping: A meaningful learning tool to promote conceptual understanding and clinical reasoning. In M. Bradshaw, \& A/ Lowenstein (Eds.), Innovative teaching strategies in nursing and related health professions. Burlington, MA: Jones and Bartlett Learning.

Perry, N. W., Huss, M. T., McAuliff, B. D., \& Galas, J. M. (1996). An active-learning approach to teaching the undergraduate psychology and law course. Teaching of Psychology, 23(2), 76-81. http://dx.doi.org/10.1207/s15328023top2302_1

Piaget, J. (1977). The development of thought: Equilibration of cognitive structures. (Trans. A. Rosen). Oxford, UK: Viking Press.

Ruckert, E., McDonald, P. L., Birkmeier, M., Walker, B., Cotton, L., Lyons, L. B., ... Plack, M. M. (2014). Using technology to promote active and social learning experiences in health professions education. Online Learning, 18(4), Oct 2014. ISSN 1092-8235. http://olj.onlinelearningconsortium.org/index.php/olj/article/view/515

Sweller, J., \& Chandler, P. (1994). Why some material is hard to learn. Cognition and Instruction, 12(3), 185-233. http://dx.doi.org/10.1207/s1532690xci1203_1 
Sweller, J., \& Chandler, P. (1991). Evidence for cognitive load theory. Cognition and Instruction, 8(4), 351-362. http://dx.doi.org/10.1207/s1532690xci0804_5

U.S. Department of Education. (2006). A test of leadership: Charting the future of U.S. higher education. A report of the commission appointed by Secretary of Education Margaret Spellings. Washington, DC.

Van Merriënboer, J. J. G., Kirschner, P. A., \& Kester, L. (2003). Taking the load off a learners mind: Instructional design for complex learning. Educational Psychologist, 38(1), 5-13. http://dx.doi.org/10.1207/S15326985EP3801_2

von Glasersfeld, E. (1989). Constructivism in education. In T. Husen, \& T. N. Postlethwaite, (Eds.), The international encyclopedia of education, supplement, 1, (p. 162-163). Oxford/ New York, NY: Pergamon Press.

\section{Notes}

Note 1. As of a year and a half ago, the course name changed to Research Methods \& Statistics after the periodic accreditation comprehensive curriculum review was conducted.

Note 2. In 2014 new Standards for Accreditation from the American Association of Colleges of Nursing (AACN) went into effect. The updated standards can be found on the AACN website. 